\title{
General Practitioners' Empathy and Health Outcomes: A Prospective Observational Study of Consultations in Areas of High and Low Deprivation
}

Stewart W. Mercer, $P b D^{1}$

Maria Higgins, MSc${ }^{1}$

Annemieke M. Bikker, MSc ${ }^{1}$

Bridie Fitzpatrick, $P b D^{1}$

Alex McConnachie, $\mathrm{PbD}^{2}$

Suzanne M. Lloyd, BSc ${ }^{2}$

Paul Little, FMedSci ${ }^{3}$

Grabam C.M. Watt, FMedSci ${ }^{1}$

${ }^{1}$ Academic Unit of General Practice and Primary Care, Institute of Health and WellBeing, University of Glasgow, Glasgow, Scotland

${ }^{2}$ Robertson Centre for Biostatistics, University of Glasgow, Glasgow, Scotland

${ }^{3}$ Primary Medical Care, Aldermoor Health Centre, University of Southampton, Southampton, England

Conflicts of interest: authors report none.

\section{CORRESPONDING AUTHOR}

Stewart W. Mercer

Academic Unit of General Practice and Primary Care

Institute of Health and WellBeing, University of Glasgow

Glasgow G12 9LX, Glasgow, Scotland

Stewart.Mercer@glasgow.ac.uk

\begin{abstract}
PURPOSE We set out to compare patients' expectations, consultation characteristics, and outcomes in areas of high and low socioeconomic deprivation, and to examine whether the same factors predict better outcomes in both settings.
\end{abstract}

METHODS Six hundred fifty-nine patients attending 47 general practitioners in high- and low-deprivation areas of Scotland participated. We assessed patients' expectations of involvement in decision making immediately before the consultation and patients' perceptions of their general practitioners' empathy immediately after. Consultations were video recorded and analyzed for verbal and nonverbal physician behaviors. Symptom severity and related well-being were measured at baseline and 1 month post-consultation. Consultation factors predicting better outcomes at 1 month were identified using backward selection methods.

RESULTS Patients in deprived areas had less desire for shared decision-making $(P<.001)$. They had more problems to discuss $(P=.01)$ within the same consultation time. Patients in deprived areas perceived their general practitioners (GPs) as less empathic $(P=.02)$, and the physicians displayed verbal and nonverbal behaviors that were less patient centered. Outcomes were worse at 1 month in deprived than in affluent groups $(70 \%$ response rate; $P<.001)$. Perceived physician empathy predicted better outcomes in both groups.

CONCLUSIONS Patients' expectations, GPs' behaviors within the consultation, and health outcomes differ substantially between high- and low-deprivation areas. In both settings, patients' perceptions of the physicians' empathy predict health outcomes. These findings are discussed in the context of inequalities and the "inverse care law."

Ann Fam Med 2016;14:117-124. doi: 10.1370/afm.1910.

\section{INTRODUCTION}

H ealth inequalities exist in most countries around the world. ${ }^{1}$ Scotland, as part of the United Kingdom, has some of the worst inequalities in Western Europe, with an ever-widening gap between the health of the rich and that of the poor. ${ }^{2,3}$ Although the social determinants of health are crucial, universal health care can help reduce disparities in health. ${ }^{4}$ The provision of primary care within the National Health Service (NHS) in the United Kingdom, however, is not configured to address the greater need in socioeconomically deprived areas. ${ }^{5}$ This mismatch has been termed the "inverse care law": the availability of good medical care tends to vary inversely with the need for it in the population served. It was first described almost 40 years ago, ${ }^{6}$ but it still holds true. ${ }^{7,8}$

In a previous study in Scotland, we reported that the increased burden of ill health and multimorbidity in socioeconomically deprived areas placed higher demands on primary care and resulted in poorer access, shorter consultations, higher general practitioner (GP) stress, and lower patient enablement. ${ }^{9,10}$ Marked variations in patient enablement among physicians were associated with differences in perceived physician empa- 
thy ${ }_{1}^{9}$ and in subsequent analysis we showed that patient enablement never occurs when the patient perceives the doctor to be low in empathy. ${ }^{11}$ Empathy may also be important for better health outcomes, ${ }^{12}$ though it is not clear whether this is influenced by patients' socioeconomic status.

In this article we report a comparison of GP consultations in areas of high and low deprivation in Scotland and analyze the factors predicting poorer or better outcomes in both high and low socioeconomic groups.

\section{METHODS}

The study comprised patient-completed questionnaires and videotaping of consultations. Our power calculation suggested that 325 patients were required to detect a correlation of 0.25 between rating of communication in the consultation and key outcomes of the consultation (symptom change and well-being), assuming an intracluster correlation of 0.03 and allowing for $20 \%$ incomplete outcomes.

\section{Recruitment}

Deprivation was measured by the Scottish Index of Multiple Deprivation (SIMD 2006) which is an areabased composite measure produced by the Scottish Government. ${ }^{13}$ Practices were recruited from the highest and lowest quartiles of deprivation (SIMD 2006 scores of patients registered with the practices) in the Greater Glasgow and Clyde Health Board Area, Scotland, United Kingdom. In the participating practices, consecutive, unselected patients aged 18 years and older were handed an information sheet by reception staff when they checked in, and a researcher then gained informed consent. Participants completed part 1 of the questionnaire before seeing the GP, saw the GP for a videotaped consultation, and completed part 2 of the questionnaire afterward. Ethical approval for the study was obtained from the Local Research Ethics Committee of the NHS, and informed consent was gained from all participating GPs and patients.

\section{Content of Patient Questionnaire}

Part 1 of the questionnaire collected the following:

- Age, sex, marital status, and postal code

- Language spoken at home

- General health over the last 12 months, measured on a 5-point scale (from "very good" to "very bad"), the categories used by Scotland's Census ${ }^{14}$

- Presence of a limiting long-term condition or disability (another item from the census) ${ }^{14}$

- Number and types of conditions (from a list of 17)

- Degree of desire to be involved in decision making ${ }^{15}$

- Number of GP visits in the last 12 months
Part 2, completed straight after the consultation, included questions on the following:

- The immediate outcome of the encounters, measured using the Patient Enablement Instrument ${ }_{1}^{16}$ which reflects the extent to which, as a result of consulting their GPs, patients feel better able to cope with and understand their conditions and keep themselves healthier. ${ }^{10}$

- Consultation length and satisfaction with the length

- Overall satisfaction

- Whether the patient would recommend the GP

- The patient's perception of the GP's empathy, assessed using the Consultation and Relational Empathy (CARE) Measure ${ }^{17}$

- Baseline main symptom severity, assessed with the Measure Yourself Medical Outcome Profile (MYMOP) ${ }_{1}^{18}$ which asks for the main symptom or problem the patient is consulting about, and asks the patient to rate its severity over the last week and his or her related well-being, both on scales of 0 ("as good as it could be") to 6 ("as bad as it could be").

- Whether the patient saw his usual doctor

- Continuity of care (how well the patient knew the doctor), measured on a single scale as in previous studies. ${ }^{19}$

- Depressive symptoms, measured with the Patient Health Questionnaire (PHQ-9), ${ }_{1}^{20}$ and anxiety, measured with the State Anxiety Index (SAI) ${ }^{21}$

The MYMOP was repeated at 1 month so that change in symptom severity and related well-being could be assessed.

\section{Observer Rating of Consultation Videos}

We assessed general practitioner verbal communication with the Measure of Patient-Centered Communication (MPCC) ${ }^{22}$ which consists of 3 components-exploring both the disease and illness experience, understanding of the whole person, and finding common ground. In total, 3 researchers coded the videos according to the manual of MPCC, and regular inter-rater reliability checks were conducted.

Nonverbal communication was assessed with a modified version of Mehrabian's schemata. ${ }^{23,24}$ Categories included number and duration of smiles, number of positive facial expressions, number of head nods, number of supportive gesticulations, gaze toward patient (duration in seconds), self/object manipulation (duration in seconds), and use of computer and notes (duration in seconds). Due to time limitations, the measurement schedule was applied to a 30 -second slice 1 minute into the consultation and a 30 -second slice 1 minute from the end of the consultation for all categories. Previous research has shown that "thin slices" are a representative way to measure nonverbal behavior. ${ }^{24,25}$ 
Two researchers coded the videotapes, and 2 interrater reliability checks were conducted.

\section{Data Analysis}

Patient, GP, and consultation characteristics and outcome measures were summarized by level of deprivation using means and standard deviations for continuous variables and counts and percentages for categorical variables. To aid with presentation and modeling, levels within categorical variables were concatenated to create binary variables. The concatenation of levels was justified both clinically and statistically.

Differences between the levels of deprivation were tested within multilevel regression models, using linear regression models for the continuous variables and logistic regression models for the binary variables. The structure of the data was such that patients were nested within GPs and GPs within practices; hence the need for multilevel modeling. In 9 practices, only 1 GP was recruited, and because it was not unreasonable to expect more variation between GPs than between practices, we wondered whether nesting at both GP and practice levels was necessary. To test this formally, we used log-likelihood ratio tests to compare 2 models, the first with GP level as a random effect and the second with both practice and GP levels as random effects, with GPs nested within practices. We tested with each outcome measure in turn as the dependent variable. The results showed no significant reductions in log-likelihood for any outcome measure with the addition of practice level to models adjusting for GP level only, thus providing evidence against the inclusion of practice level. As a result, we assessed differences between the levels of deprivation using multi-level models adjusting for GP as a random effect with fixed effects for patient age, sex, and area of deprivation.

We identified predictors of outcome (change from baseline) at 1 month using multilevel linear and logistic regression models as described above. In addition to the baseline score, age, sex, and deprivation level, we examined each potential predictor in turn, and all significant predictors identified by this approach were included in a new model. We then used a backward model selection approach to identify the independent predictors of outcome. At each stage, the baseline score, age, sex, and deprivation level were forced into the model, regardless of their significance. We tested interactions between outcome and deprivation level once the independent predictors were identified. All analyses were performed using SAS version 9.2 (SAS Institute, Inc).

\section{RESULTS}

\section{Practice Characteristics}

Twenty practices, $47 \mathrm{GPs}$, and 659 patients participated (13 practices, $25 \mathrm{GPs}$, and 356 patients in high-deprivation areas; 7 practices, 22 GPs, and 303 patients in low-deprivation areas). Overall, approximately $50 \%$ of patients approached agreed to take part. Mean practice size (number of registered patients) was 5,108 in the high-deprivation areas and 7,678 in the low-deprivation areas $(P<.01)$. The mean deprivation scores of the participating practices and patients were very similar to the mean scores of all practices in their respective deprivation areas (Supplemental Appendix, available at http://annfammed.org/ content/14/2/117/suppl/DC1). Age and sex of participating GPs did not differ significantly between the 2 areas (results not shown). All practices operated on a 10 -minute booking schedule for patient appointments, which is standard in the United Kingdom.

\section{Patient Characteristics}

Average patient age and sex were similar in the highand low-deprivation groups (Table 1). Most patients spoke English as their first language (97\% and 96\% in the high- and low-deprivation areas, respectively). In the high-deprivation group, fewer patients were living
Table 1. Patient Demographic and Baseline Characteristics

\begin{tabular}{|c|c|c|c|}
\hline \multirow[b]{2}{*}{ Characteristic } & \multicolumn{2}{|c|}{ Deprivation Area } & \multirow{2}{*}{$\begin{array}{c}P \\
\text { Value }\end{array}$} \\
\hline & Low & High & \\
\hline Age in $y$, mean (SD) & $50.50(19.13)$ & $51.45(17.07)$ & .60 \\
\hline Female, No. (\%) & $199(66.3)$ & $223(62.6)$ & .50 \\
\hline Married/living with partner, No. (\%) & $174(58.6)$ & $140(39.8)$ & $<.001$ \\
\hline Chronic conditions, No. (SD) & $1.6(1.4)$ & $2.2(1.9)$ & $<.001$ \\
\hline$\geq 3$ Chronic conditions, No. (\%) & $68(22.4)$ & $131(36.8)$ & $<.001$ \\
\hline Disabled by condition, No. (\%) & $102(34.1)$ & $182(51.7)$ & $<.001$ \\
\hline Good or better rating of health, No. (\%) & $185(62.3)$ & $142(40.5)$ & $<.001$ \\
\hline Anxiety score, mean (SD) ${ }^{a}$ & $10.82(3.00)$ & $11.59(3.32)$ & .003 \\
\hline Depression score, mean $(S D)^{a}$ & $5.46(5.45)$ & $7.28(6.59)$ & $<.001$ \\
\hline$\geq 2$ Problems to discuss, No. (\%) & $129(42.9)$ & $192(54.1)$ & .01 \\
\hline $\begin{array}{l}\text { Desire for involvement in decision mak- } \\
\text { ing, mean (SD) }\end{array}$ & $2.43(0.61)$ & $2.05(0.65)$ & $<.001$ \\
\hline \multicolumn{4}{|c|}{$\begin{array}{l}\text { Note: } P \text { values for differences between areas of deprivation are extracted from multi-level linear or logistic } \\
\text { regression models that include fixed effects for age and sex and a random effect for GP level. }\end{array}$} \\
\hline \multicolumn{4}{|c|}{$\begin{array}{l}\text { a Possible anxiety scores ranged from } 6 \text { to } 24 \text { (higher meaning worse anxiety), depression scores from } 0 \text { to } \\
27 \text { (higher meaning worse depression), and desire for involvement from } 1 \text { to } 5 \text { (where } 1 \text { means doctor alone } \\
\text { should decide and } 5 \text { means patient alone should decide). }\end{array}$} \\
\hline
\end{tabular}


with a partner and more had multimorbidity, disability, poor general health, anxiety, and depression than in the more affluent group (Table 1). Deprived patients had more problems to discuss in the consultation but less desire to be involved in decision-making (Table 1 and Supplemental Appendix Table 2, available at http:// annfammed.org/content/14/2/117/suppl/DC1). When asked, "Who should decide the treatment choice?" more than $70 \%$ of patients in deprived areas thought it should mainly or solely be the doctor, compared with $43 \%$ of patients in more affluent areas (Figure 1). Reason for consulting and the body system affected did not differ significantly between the 2 socioeconomic groups (Supplemental Appendix, available at http:// annfammed.org/content/14/2/117/suppl/DC1).

\section{Characteristics of the Clinical Encounters}

\section{Videos}

Full details of the coding for GP verbal and nonverbal communication and the inter-rater reliability coefficient (measured as intraclass correlation) are given in the Supplemental Appendix, available at http://annfammed.org/content/14/2/117/suppl/DC1. The average intraclass correlation was 0.86 for verbal and greater than 0.8 for nonverbal communications.

GPs' overall verbal communication was significantly less patient-centered in the deprived group than in the affluent (Table 2). This was mainly due to a lower score for component 3 of the MPCC ("finding common

ground"). GP nonverbal communication was also significantly poorer in the high-deprivation areas in terms of supportive facial expressions and time spent looking at the patient rather than the computer (Table 2). Measured consultation length (approximately 9 minutes face-to-face time) did not differ significantly between the 2 groups. Full details of the other nonverbal scores are given in the Supplemental Appendix, available at http://annfammed.org/content/14/2/117/suppl/DC1.

\section{Patient's Views}

Patients from the high-deprivation areas recorded lower CARE Measure scores (lower perceived GP empathy) than those from the more affluent areas, even though the more deprived group reported knowing the doctors better (Table 2).

\section{Outcomes of Clinical Encounters at 1 Month}

A total of $464(70 \%)$ of the 659 patients responded to the 1 -month follow-up questionnaire $(78 \%$ and $63 \%$ for low- and high-deprivation areas, respectively, $P<.001)$. Patients who responded to the follow-up questionnaire were older than the nonresponders (53 vs 46 years $; \quad P<.001)$, were more likely to be living with a partner $(52 \%$ vs $39 \% ; P<.01)$, and had lower baseline MYMOP symptom scores (4.6 vs $5.1 ; P<.001)$ (Supplemental Appendix, available at http://annfammed.org/ content/14/2/117/suppl/DC1).

Patients in deprived areas reported higher symptom severity and worse well-being than patients in affluent areas at base-

Figure 1. Patients' desire for involvement in management decision making.

High-deprivation practice area $\quad \square$ Low-deprivation practice area

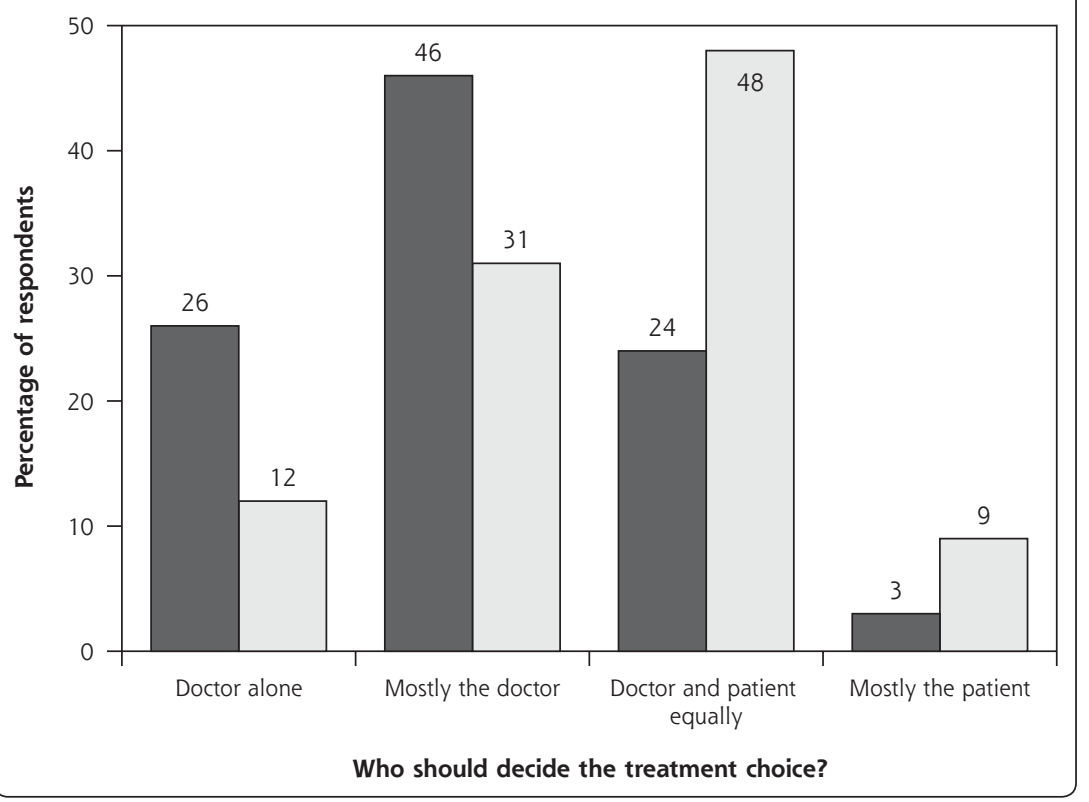
line (that is, at consultation) and 1 month later (Table 3). Patients from deprived areas also had significantly smaller MYMOP change scores (follow-up score minus baseline score) for symptom improvement (Table 3). The intracluster correlation for the MYMOP scores at baseline were 0.023 and 0.025 for symptom and well-being measures, respectively, indicating a relatively low cluster effect.

\section{Predictors of Outcome at 1 Month}

Multilevel, multi-regression analysis identified 8 baseline factors that were independently predictive of MYMOP symptom severity scores at 1 month after the consultation: MYMOP symptom severity at baseline, multimorbidity count, general health, 
Table 2. Characteristics of the Clinical Encounters

\begin{tabular}{|c|c|c|c|c|}
\hline \multirow[b]{2}{*}{ Variable } & \multicolumn{2}{|c|}{ Level of Deprivation } & \multirow[b]{2}{*}{$\begin{array}{l}\text { Effect Size } \\
\text { (Cohen's d) }\end{array}$} & \multirow[b]{2}{*}{$P$ Value } \\
\hline & $\begin{array}{c}\text { Low } \\
\text { Mean (SD) }\end{array}$ & $\begin{array}{c}\text { High } \\
\text { Mean (SD) }\end{array}$ & & \\
\hline \multicolumn{5}{|l|}{ GP verbal communication } \\
\hline Patient-centered score total & $1.42(0.45)$ & $1.27(0.49)$ & 0.319 & .02 \\
\hline Component 1: Exploring both disease and illness experience & $0.28(0.13)$ & $0.25(0.13)$ & 0.231 & .08 \\
\hline Component 3: Understanding of the whole person & $0.34(0.38)$ & $0.29(0.38)$ & 0.132 & .22 \\
\hline Component 3: Finding common ground & $0.81(0.14)$ & $0.72(0.18)$ & 0.559 & $<.001$ \\
\hline \multicolumn{5}{|l|}{ GP nonverbal communication } \\
\hline Smiles & $0.38(.65)$ & $0.29(0.58)$ & 0.146 & .20 \\
\hline Supportive facial expressions & $1.78(1.76)$ & $1.27(1.41)$ & 0.357 & .04 \\
\hline GP Head nods & $6.05(5.53)$ & $4.05(5.88)$ & 0.350 & .08 \\
\hline GP seconds looking at patient & $21.51(9.10)$ & $17.94(10.23)$ & 0.369 & .01 \\
\hline GP seconds looking at computer & $6.18(8.81)$ & $9.63(10.62)$ & -0.353 & .02 \\
\hline \multicolumn{5}{|l|}{ Consultation length and continuity } \\
\hline Length of consultation (minutes) & $9.24(4.17)$ & $9.17(4.11)$ & 0.017 & .90 \\
\hline How well patient knows GP & $3.48(1.29)$ & $4.04(1.03)$ & -0.085 & .001 \\
\hline \multicolumn{5}{|l|}{ Empathy and enablement } \\
\hline Patients' score of GP empathy (CARE Measure) & $4.50(0.62)$ & $4.34(0.66)$ & 0.250 & .02 \\
\hline Patient enablement (PEI) & $4.62(3.29)$ & $4.28(3.45)$ & 0.101 & .20 \\
\hline
\end{tabular}

GP visits in the last 12 months, duration of symptoms, depression score, consultation length, and perceived GP empathy (CARE measure) (Table 4). Six baseline factors were predictive of well-being outcomes:
MYMOP well-being score at baseline, general health, GP visits in the last 12 months, duration of symptoms, depression score, and perceived GP empathy. Only 2 factors, higher baseline MYMOP score and higher perceived GP empathy, predicted bet-

\section{Table 3. Outcome Measures by Level of Deprivation}

\begin{tabular}{|c|c|c|c|c|}
\hline \multirow[b]{2}{*}{ Variable } & \multicolumn{2}{|c|}{ Level of Deprivation } & \multirow[b]{2}{*}{$\begin{array}{l}\text { Effect Size } \\
\text { (Cohen's d) }\end{array}$} & \multirow[b]{2}{*}{$P$ Value } \\
\hline & $\begin{array}{c}\text { Low } \\
\text { Mean (SD) }\end{array}$ & $\begin{array}{c}\text { High } \\
\text { Mean (SD) }\end{array}$ & & \\
\hline \multicolumn{5}{|l|}{ MYMOP symptom score ${ }^{a}$} \\
\hline Baseline & $\begin{array}{l}4.58(1.50) \\
n=266\end{array}$ & $\begin{array}{l}4.90(1.56) \\
n=310\end{array}$ & -0.209 & .01 \\
\hline 1 Month after baseline & $\begin{array}{l}2.79(1.78) \\
\mathrm{n}=221\end{array}$ & $\begin{array}{l}3.48(2.01) \\
n=211\end{array}$ & -0.363 & $<.001$ \\
\hline Change from baseline & $\begin{array}{l}-1.76(2.10) \\
n=200\end{array}$ & $\begin{aligned} &-1.21(2.13) \\
& \mathrm{n}=188\end{aligned}$ & -0.260 & .01 \\
\hline \multicolumn{5}{|l|}{ MYMOP well-being score ${ }^{a}$} \\
\hline Baseline & $\begin{array}{l}3.29(1.63) \\
n=287\end{array}$ & $\begin{array}{l}3.74(1.78) \\
n=340\end{array}$ & -0.264 & .005 \\
\hline 1 Month after baseline & $\begin{array}{l}2.78(1.62) \\
n=225\end{array}$ & $\begin{array}{l}3.53(1.91) \\
n=211\end{array}$ & -0.424 & $<.001$ \\
\hline Change from baseline & $\begin{array}{l}-0.49(1.90) \\
n=217\end{array}$ & $\begin{array}{l}-0.20(2.09) \\
n=203\end{array}$ & -0.145 & .15 \\
\hline \multicolumn{5}{|c|}{ GP = general practitioner; MYMOP = Measure Yourself Medical Outcome Profile. } \\
\hline \multicolumn{5}{|c|}{$\begin{array}{l}\text { a MYMOP scores are generated by the patient on a } 7 \text { point scale from } 0 \text { ("as good as it could be") to } 6 \text { ("as } \\
\text { bad as it could be"). Thus high mean scores at baseline or follow-up reflect worse symptoms and well-being. } \\
\text { Change scores are calculated as score at } 1 \text { month minus score at baseline. }\end{array}$} \\
\hline \multicolumn{5}{|c|}{$\begin{array}{l}\text { Note: } P \text { values for differences between areas of deprivation are extracted from multi-level linear regression } \\
\text { models that include fixed effects for age and sex and a random effect for GP level. }\end{array}$} \\
\hline
\end{tabular}
ter outcomes. There were no significant interaction effects between deprivation group and any of these predictors of MYMOP outcomes, indicating that these predictors did not vary between high and low deprivation settings.

Although some of the baseline factors were significantly correlated (multimorbidity count, general health, PHQ-9 score, and consultation rates) these correlations were all relatively weak (less than 0.4 ), variance inflation factors were all less than 1.0, and tolerance was less than 0.6. Thus multicollinearity was not considered to be a significant problem. The correlation matrix and the full unadjusted and adjusted analysis are shown in the Supplemental Appendix, available at http://annfammed.org/ content/14/2/117/suppl/DC1). 


\section{Table 4. Baseline Factors Predicting Outcomes at 1 Month After Consultation}

\begin{tabular}{|c|c|c|}
\hline Covariate (n) & $\begin{array}{c}\text { Adjusted Parameter } \\
\text { Estimate } \\
\text { Value }(95 \% \mathrm{CI})\end{array}$ & $P$ Value \\
\hline \multicolumn{3}{|c|}{ Predictors of MYMOP symptom scores at 1 month } \\
\hline Baseline MYMOP score (388) & $-0.71(-0.83$ to -0.59$)$ & $<.001$ \\
\hline High deprivation level (432) & $0.16(-0.24$ to 0.56$)$ & .43 \\
\hline $10-y$ Increase in age (430) & $-0.03(-0.14$ to .08$)$ & .61 \\
\hline Male sex (430) & $-0.08(-0.49$ to .31$)$ & .68 \\
\hline Multiple morbidity count (432) & $.13(0.01$ to 0.26$)$ & .03 \\
\hline Rating of health (423) & $.25(0.02$ to 0.47$)$ & .03 \\
\hline GP Visits in past year (401) & $.05(0.01$ to 0.08$)$ & .01 \\
\hline Duration of symptoms > 4 wk (378) & $.53(0.15$ to 0.92$)$ & .006 \\
\hline PHQ-9 Baseline score (417) & .05 (0.02 to 0.09$)$ & .003 \\
\hline Minutes spent with GP (423) & $.06(0.02$ to 0.11$)$ & .008 \\
\hline CARE Measure score (432) & $-0.40(-0.70$ to -0.10$)$ & .01 \\
\hline \multicolumn{3}{|c|}{ Predictors of MYMOP well-being scores at 1 month } \\
\hline Baseline MYMOP score (420) & $-0.83(-0.94$ to -0.72$)$ & $<.001$ \\
\hline High deprivation (436) & $0.24(-0.11$ to 0.59$)$ & .18 \\
\hline $10-y$ Increase in age (434) & $-0.01(-0.11$ to 0.09$)$ & .80 \\
\hline Male sex (434) & $-0.18(-0.53$ to 0.17$)$ & .31 \\
\hline Rating of health (428) & $0.38(0.19$ to 0.58$)$ & $<.001$ \\
\hline Duration of symptoms > 4 wk (376) & $0.42(0.09$ to 0.75$)$ & .01 \\
\hline GP visits in past year (406) & $0.04(0.01$ to 0.07$)$ & .01 \\
\hline PHQ-9 baseline score (421) & 0.06 (0.03 to 0.09$)$ & $<.001$ \\
\hline CARE measure score (436) & $-0.27(-0.53$ to -0.02$)$ & .04 \\
\hline \multicolumn{3}{|c|}{$\mathrm{CARE}=$ consultation and relational empathy; $\mathrm{GP}=$ general practitioner; $\mathrm{PHQ}-9=$ patient health questionnaire. } \\
\hline \multicolumn{3}{|c|}{$\begin{array}{l}\text { Note: For both outcome measures, the baseline MYMOP score, age, sex, and deprivation level were included in } \\
\text { the adjusted regardless of significance. The full unadjusted and adjusted results are shown in the Supplemental } \\
\text { Appendix, available at http://annfammed.org/content/14/2/117/suppl/DC1. A negative score in the parameter } \\
\text { estimate (eg, baseline MYMOP scores) indicates a positive effect of that variable on outcomes at } 1 \text { month } \\
\text { (because higher MYMOP scores represent worse symptoms and worse well-being). Depending on the nature of } \\
\text { the covariate measured, the parameter estimate can be interpreted as the mean difference in the outcome vari- } \\
\text { able associated with a 10-year increase in age, a 1-point increase in other continuous or ordinal predictors, or } \\
\text { being in the specified subgroup (compared with the other) for binary predictors. }\end{array}$} \\
\hline
\end{tabular}

Patient-reported outcomes (MYMOP scores) 1 month after the consultation were worse in deprived areas than in affluent ones. Several factors relating to patients' baseline health problems influenced outcomes at 1 month. GP empathy was the only consultation factor that predicted better outcomes (symptoms and well-being) in both high and low deprivation groups.

\section{Strengths and Weaknesses}

As far as we are aware, the current research is the largest and most comprehensive study ever conducted on consultations and health outcomes in high- and low-deprivation areas using both patient- and observer-rated methods. We powered the study on a sample size of 325 patients with an assumed intracluster correlation of 0.03 ; in the actual study we collected outcome data on 464 patients and found a lower intra-cluster correlation (0.024) Thus the study was sufficiently powered to detect significant effects on outcomes.

One weakness in the study was that only $50 \%$ of patients asked to participate agreed ${ }_{i}$ hence the sample cannot be described as fully representative. The patients who did participate, however, had levels of deprivation similar on average to those of registered patients, and the participating practices were representative of all practices in the sampling frame in terms of deprivation (Supplemental Appendix, available at http://annfammed.org/ content/14/2/117/suppl/DC1). Although we achieved a good overall response rate to the follow-up patient questionnaire at 1 month (greater than $70 \%$ ), patients who responded were significantly older, were more likely to be living with a partner, and reported lower symptom severity at baseline than those who did not respond. Patients living in deprived areas had a lower response rate $(63 \%)$ than those in affluent areas $(78 \%)$. The only 2 significant differences between responders and non-responders, however, were found in the high-deprivation group (age and marital status), and neither of these variables had any significant effect on outcomes in the modeling of predictors of outcome 
(Table 4). Thus it is unlikely that the lower response rate in the deprived group had any meaningful impact on the findings in terms of predictors of outcomes at 1 month.

The consultation findings require some further qualification. First, the "clinical significance" of the statistical differences observed between the consultation measures in high- and low-deprivation areas is not known, and the effect sizes were generally small to medium (Table 2). The main difference between the high- and low-deprivation groups in observerrated patient-centered care was in component 3 of the MPPC ("finding common ground"). This rates the GP in terms of discussion and agreement with the patient on problem definition and treatment goals. Given that the majority of patients in the deprived group stated before the consultation that they did not wish to be involved in these decisions, it may be inappropriate to label these GPs as less "patient-centered"; instead, perhaps we should be asking whether generic definitions and measures of patient-centered care are valid in high-deprivation settings.

In terms of the outcomes at 1 month, a change in the MYMOP score of 1.0 or more is regarded as clinically significant, and a change of between 0.5 and 1.0 of likely clinical significance. ${ }^{26}$ In the current study, the changes in symptom scores at 1 month in both groups were well above 1.0 and the difference between deprived and affluent groups was greater than 0.5. This suggests that the difference in outcomes between the 2 groups was of likely clinical significance.

\section{Relationship to Published Literature}

The high level of need in deprived areas found in the present study reflects our previous work on the epidemiology of multimorbidity in Scotland ${ }^{27}$ The low desire of patients in deprived areas to be actively involved in decision making also agrees with other studies. ${ }^{28-30}$ Our finding that consultations in deprived areas were less patient-centered agrees with a review of the literature that found that physicians are generally much more directive with patients of low educational status. ${ }^{31}$

Perceived GP empathy (as gauged by the CARE measure) was also lower in the deprived group than the affluent, and empathy was a significant independent predictor of better outcomes at 1 month in both deprived and affluent groups. This adds to the growing evidence base on the importance of physician empathy in achieving good patient outcomes. ${ }^{12}$ There is also increasing evidence that physician empathy can be enhanced through specific interventions. ${ }^{32}$

There was no difference in consultation length between the most and least deprived areas in the pres- ent study. This is unsurprising, since currently the GP contract in the United Kingdom sets consultation length at 10 minutes, irrespective of the practices' deprivation profile. Given that patients in the more deprived areas had higher morbidity and more problems to discuss, however, it can be argued that more time in the consultation is required in deprived areas. In the present study, however, longer consultations were actually associated with worse patient outcomes at 1-month follow-up. Similarly, in previous related work, we have found that longer consultations in deprived areas were associated with lower patient enablement and higher GP stress. ${ }^{9}$ We speculate that longer consultations within a schedule built on routine 10-minute appointments may indicate problems of high complexity, such as medically unexplained symptoms. This may also be why higher consultation frequency was also related to poorer outcomes. Thus improving outcomes may require planning and structuring consultations to be longer, rather than forcing stressed doctors to run late. We have previously found that a modest planned increase in consultation length for patients with complex problems in a deprived area resulted in higher patient enablement and lower GP stress. ${ }^{33}$ Further work is ongoing on this issue.

\section{Policy Implications}

Most of the factors that predicted poorer outcomes in the present study related to the patients' baseline health and social characteristics (severity and duration of symptoms, number of chronic conditions, mental health problems, poor general health, and living in deprived areas). Despite the higher levels of unmet need in deprived areas, GP distribution in Scotland is flat across deprivation levels. ${ }^{34}$ Thus the perverse "inverse care law" continues to hold in Scotland, limiting the ability of GPs to more fully respond to the needs of patients in deprived areas. ${ }^{7-9}$ It is also of interest that patients in the high-deprivation areas had little desire for shared decision making, and this did not influence outcomes in either deprivation group, adding to the limited evidence base on this topic. ${ }^{35}$

Patients living in areas of high deprivation in Scotland report poorer outcomes from general practice consultations than those living in less deprived settings. High levels of need, as reflected in more multimorbidity, poorer health, and more mental health problems, and higher severity of symptoms at time of consultation all impacted significantly on these poorer outcomes. Policies that address the wider social determinants of health are clearly crucial in improving health in deprived areas, but improving consultation quality by reversing the inverse care law could also contribute to better outcomes. 
To read or post commentaries in response to this article, see it online at http://www.annfammed.org/content/14/2/117.

Key words: physician empathy; primary health care; socioeconomic status; outcome and process assessment

Submitted September 6, 2011; submitted, revised, December 12, 2015: accepted January 5, 2016.

Funding support: The study was funded by the Chief Scientist Office, Scottish Government, grant number CZH/4/267.

Acknowledgments: We would like to thank all the GPs and patients who took part in this study.

Supplementary materials: Available at http://www.AnnFamMed. org/content/14/2/117/suppl/DC1/.

\section{References}

1. Commission on Social Determinants of Health. Closing the Gap In a Generation: Health Equity Through Action on the Social Determinants of Health. Geneva, Switzerland: World Health Organization; 2008.

2. Audit Scotland. Health inequalities in Scotland. http://www.auditscotland.gov.uk/docs/health/2012/nr_121213_health_inequalities. pdf. Published Dec 2012.

3. The Scottish Government. Long-term monitoring of health inequalities: headline indicators. http://www.scotland.gov.uk/ Resource/0040/00406782.pdf. Published Oct 2012.

4. Barr B, Bambra C, Whitehead M. The impact of NHS resource allocation policy on health inequalities in England 2001-11: longitudinal ecological study. BMJ. 2014;348:g3231.

5. Hart JT. The inverse care law. Lancet. 1971;1(7696):405-412.

6. Watt G. The inverse care law today. Lancet. 2002;360(9328): 252-254.

7. Mercer SW, Guthrie B, Furler J, Watt GCM, Hart JT. Multimorbidity and the inverse care law in primary care. BMJ. 2012;344:e4152.

8. Mackay D, Sutton M, Watt G. Deprivation and volunteering by general practices: cross sectional analysis of a national primary care system. BMJ. 2005;331(7530):1449-1451.

9. Mercer SW, Watt GC. The inverse care law: clinical primary care encounters in deprived and affluent areas of Scotland. Ann Fam Med. 2007;5(6):503-510.

10. Howie JGR, Heaney DJ, Maxwell M. Measuring Quality in General Practice: Pilot Study of a Needs, Process and Outcome Measure. London, England: The Royal College of General Practitioners; 1997.

11. Mercer SW, Jani BD, Maxwell M, Wong SY, Watt GC. Patient enablement requires physician empathy: a cross-sectional study of general practice consultations in areas of high and low socioeconomic deprivation in Scotland. BMC Fam Pract. 2012;13:6.

12. Derksen F, Bensing J, Lagro-Janssen A. Effectiveness of empathy in general practice: a systematic review. Br J Gen Pract. 2013;63 (606): e76-e84.

13. The Scottish Government. Scottish Index of Multiple Deprivation (SIMD) 2006. http://www.gov.scot/SIMD2006report. Published Oct 2006.

14. Scotland's Census. http://www.scotlandscensus.gov.uk. Accessed February 24, 2016.

15. Deber RB, Kraetschmer N, Irvine J. What role do patients wish to play in treatment decision making? Arch Intern Med. 1996;156(13): 1414-1420.
16. Howie JGR, Heaney DJ, Maxwell M, Walker JJ, Freeman GK, Rai $\mathrm{H}$. Quality at general practice consultations: cross sectional survey. BMJ. 1999;319(7212):738-743

17. Mercer SW, McConnachie A, Maxwell M, Heaney D, Watt GCM. Relevance and practical use of the Consultation and Relational Empathy (CARE) Measure in general practice. Fam Pract. 2005;22(3):328-334.

18. Paterson C. Measuring outcomes in primary care: a patient generated measure, MYMOP, compared with the SF-36 health survey. BMJ. 1996;312(7037):1016-1020.

19. Howie JG, Heaney DJ, Maxwell M, Walker JJ, Freeman GK. Developing a 'consultation quality index' (CQI) for use in general practice. Fam Pract. 2000;17(6):455-461.

20. Kroenke K, Spitzer RL, Williams JB. The PHQ-9: validity of a brief depression severity measure. J Gen Intern Med. 2001;16(9):606-613.

21. Marteau TM, Bekker H. The development of a six-item short-form of the state scale of the Spielberger State-Trait Anxiety Inventory. $\mathrm{Br}$ J Clin Psychol. 1992;31(3):301-3066.

22. Brown JB, Stewart MA, Ryan BL. Assessing communication between patients and physicians: the measure of patient-centred communication. Paper no. 95-2, $2^{\text {nd }}$ ed. London, Ontario, Canada: Thames Valley Family Practice Research Unit and Centre for Studies in Family Medicine, 2001.

23. Mehrabian A. Non Verbal Communication. Chicago, IL: Aldine Atherton Inc, 1972.

24. Little $P$, White $P$, Kelly J, et al. Verbal and non-verbal behaviour and patient perception of communication in primary care: an observational study. Br J Gen Pract. 2015;65(634):e357-e365.

25. Ambady N, Koo J, Rosenthal R, Winograd CH. Physical therapists' nonverbal communication predicts geriatric patients' health outcomes. Psychol Aging. 2002;17(3):443-452.

26. Welcome to MYMOP: Frequently Asked Questions. University of Bristol Centre for Academic Primary Care. http://www.bris.ac.uk/ primaryhealthcare/resources/mymop/. Accessed February 4, 2016.

27. Barnett K, Mercer SW, Norbury M, Watt G, Wyke S, Guthrie B. Epidemiology of multimorbidity and implications for health care, research, and medical education: a cross-sectional study. Lancet. 2012;380(9836):37-43.

28. McKinstry B. Do patients wish to be involved in decision making in the consultation? A cross sectional survey with video vignettes. $B M J$. 2000;321(7265):867-871.

29. Swenson SL, Buell S, Zettler P, White M, Ruston DC, Lo B. Patientcentered communication: do patients really prefer it? J Gen Intern Med. 2004;19(11):1069-1079.

30. Smith SK, Dixon A, Trevena L, Nutbeam D, McCaffery KJ. Exploring patient involvement in healthcare decision making across different education and functional health literacy groups. Soc Sci Med. 2009;69(12):1805-1812.

31. Verlinde E, De Laender N, De Maesschalck S, Deveugele M, Willems $\mathrm{S}$. The social gradient in doctor-patient communication. Int J Equity Health. 2012;11(12):12.

32. Batt-Rawden SA, Chisolm MS, Anton B, Flickinger TE. Teaching empathy to medical students: an updated, systematic review. Acad Med. 2013;88(8):1171-1177.

33. Mercer SW, Fitzpatrick B, Gourlay G, Vojt G, McConnachie A, Watt GC. More time for complex consultations in a high-deprivation practice is associated with increased patient enablement. $\mathrm{Br} J \mathrm{Gen}$ Pract. 2007;57(545):960-966.

34. McLean G, Guthrie B, Mercer SW, Watt GCM. General practice funding underpins the persistence of the inverse care law: crosssectional study in Scotland. Br J Gen Pract. 2015;65(641):e799-e805.

35. Shay LA, Lafata JE. Where is the evidence? A systematic review of shared decision making and patient outcomes. Med Decis Making. 2015;35(1):114-131. 